
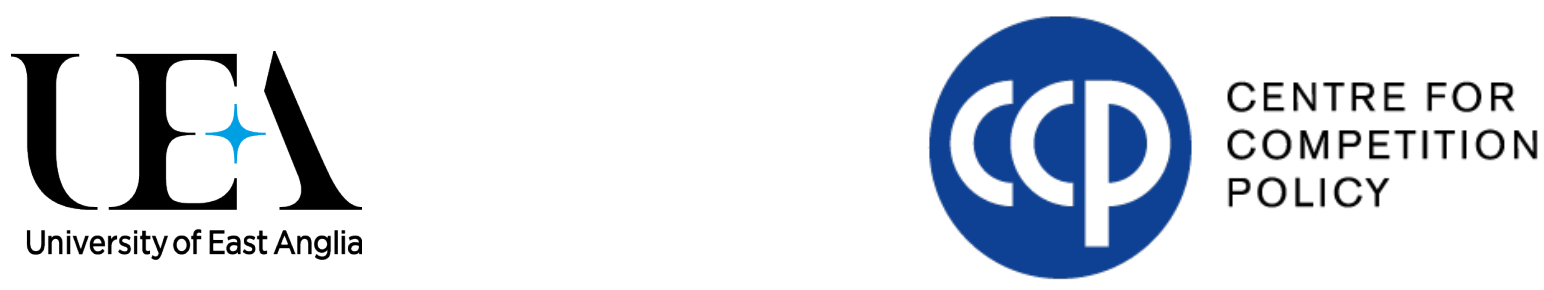

\title{
Market Investigations for Digital Platforms: Panacea or Complement?
}

\author{
Amelia Fletcher \\ Centre for Competition Policy \\ University of East Anglia \\ CCP Working Paper 20-06
}

There is a growing international consensus that standard competition law is inadequate for addressing the panoply of competition problems arising in digital platform markets. Alongside a proposal for ex ante regulation in this arena, the European Commission is considering the introduction of a 'New Competition Tool' which is broadly modelled on the UK Market Investigation instrument.

This paper abstracts from the specifics of the EU situation and considers the pros and cons of market investigations in the context of the UK regime. It concludes that the tool is a valuable addition to the standard competition law toolkit, and that this is likely to be true also at EU level, both for digital platforms and more widely. However, because the tool is potentially so powerful and flexible, it merits strong procedural checks and balances, to guard against confirmation bias or politicisation. The tool also has important limitations and thus should not be viewed as a full solution to the issues raised by digital platforms, but rather as a valuable complementary tool alongside new ex ante regulation. Interoperability is discussed as one example where the tools could valuably be used alongside each other

Contact Details:

Amelia Fletcher Amelia.Fletcher@uea.ac.uk 


\title{
Market Investigations for Digital Platforms: Panacea or Complement?
}

\author{
Amelia Fletcher \\ Centre for Competition Policy \\ University of East Anglia*
}

\section{Summary}

There is a growing international consensus that standard competition law is inadequate for addressing the panoply of competition problems arising in digital platform markets.

Alongside a proposal for ex ante regulation in this arena, the European Commission is considering the introduction of a 'New Competition Tool' which is broadly modelled on the UK Market Investigation instrument.

This paper abstracts from the specifics of the EU situation and considers the pros and cons of market investigations in the context of the UK regime. It concludes that the tool is a valuable addition to the standard competition law toolkit, and that this is likely to be true also at EU level, both for digital platforms and more widely. However, because the tool is potentially so powerful and flexible, it merits strong procedural checks and balances, to guard against confirmation bias or politicisation. The tool also has important limitations and thus should not be viewed as a full solution to the issues raised by digital platforms, but rather as a valuable complementary tool alongside new ex ante regulation. Interoperability is discussed as one example where the tools could valuably be used alongside each other.

\footnotetext{
* The author is also a Non-Executive Board Member at the Competition Markets Authority, and was a member of the UK Government-commissioned Digital Competition Expert Panel which published Unlocking Digital Competition in March 2019. The author would like to thank Martin Cave, Steve Davies, Alexandre De Streel, Paul Dobson, Richard Feasey, Adam Land, Liza Lovdahl Gormson, Bruce Lyons, Philip Marsden and Massimo Motta for useful comments. However, all views expressed here are her own. This work was supported by the Economic and Social Research Council [grant number ES/P008976/1].
} 


\section{Introduction}

There is a growing international consensus that standard competition law, while valuable, is inadequate for addressing the panoply of competition problems arising in digital platform markets. In 2019 alone, there were a wide array of policy reports published, across many different jurisdictions, all identifying concerns with existing powers in this area and the need for reform. ${ }^{1}$ A number of jurisdictions are currently considering legislative changes to address these issues, with Germany proposing to amend its competition law to play a more regulatory role ${ }^{2}$, while the UK, Australia and Japan are all taking practical steps towards introducing pro-competitive ex ante regulation. ${ }^{3}$

In its own quest to address these concerns, the European Commission is currently considering the potential introduction of two new legal powers: a 'New Competition Tool' 4 and an 'ex ante regulatory instrument for large online platforms'. ${ }^{5} \mathrm{~A}$ menu of different variants of both are offered up for comment.

\footnotetext{
${ }^{1}$ The three most prominent reports are those from the EC (J. Crémer, Y-A. de Montjoye and H. Schweitzer, Competition policy for the digital era, Report to the European Commission, 2019); UK (J. Furman, D. Coyle, A. Fletcher, D. McAuley and P. Marsden, Unlocking Digital Competition, 2019); US (F. Scott Morton, Bouvier, P., Ezrachi, A., Jullien, A., Katz, R., Kimmelman, G., Melamed, D. and J. Morgenstern, Committee for the Study of Digital Platforms, Market Structure and Antitrust Subcommittee, Stigler Center for the Study of the Economy and the State, 2019). In addition, there have been reports from Australia (ACCC, Digital Platforms Enquiry: Final Report, 2019); Benelux (Joint memorandum of the Belgian, Dutch and Luxembourg competition authorities on challenges faced by competition authorities in a digital world, 2019); BRICS (BRICS in the digital economy: Competition policy in practice, 2019); France (G. Longuet et al., Report at the French Senate on digital sovereignty, 2019); Germany (M. Schallbruch, H. Schweitzer and A. Wambach, A new competition framework for the digital economy: Report by the Commission 'Competition Law 4.0', 2019); Italy (AGCM, AGCOM, AGPDP, Big Data Joint Survey, 2019); Japan (FTC, Report regarding trade practices on digital platforms, 2019); Netherlands (Ministry of Economic Affairs and Climate Policy, Future-proofing of competition policy in regard to online platforms, 2019); Portugal (Autoridade da Concurrencia, Digital Ecosystems, Big Data and Algorithms, 2019); UNCTAD (Competition issues in the digital economy, 2019).

${ }^{2}$ For an unofficial English translation, see: https://www.d-kart.de/wp-content/uploads/2020/02/GWB10-EnglTranslation-2020-02-21.pdf.

${ }^{3}$ See for Australia (Government Response and Implementation Roadmap for the Digital Platforms Inquiry, 2019, https://treasury.gov.au/publication/p2019-41708 and for the UK (Digital markets taskforce: terms of reference, 2020 (https://www.gov.uk/government/publications/digital-markets-taskforce-terms-ofreference/digital-markets-taskforce-terms-of-reference--3). For Japan, an English language description of Government proposals can be found at: White and Case (2020) The Japan Cabinet proposed Direction of Bill for Digital Platform Transparency Act, https://www.whitecase.com/sites/default/files/2020-01/the-japan-cabinetproposed-direction-of-bill-for-digital-platform-transparency-act.pdf.

4 European Commission (2020) Antitrust: Commission consults stakeholders on a possible new competition tool, Press release, 2 June 2020, https://ec.europa.eu/commission/presscorner/detail/en/ip_20_977.

${ }^{5}$ European Commission, (2020) Inception Impact Assessment. Digital Services Act package: Ex ante regulatory instrument for large online platforms with significant network effects acting as gate-keepers in the European Union's internal market, 2 June 2020. The most relevant option is Option 3: "Adopt a new and flexible ex ante regulatory framework for large online platforms acting as gatekeepers" This includes two sub-options: "3a. Prohibition or restriction of certain unfair trading practices by large online platforms acting as gatekeepers ("blacklisted" practices)" and "3b. Adoption of tailor-made remedies addressed to large online platforms acting as gatekeepers on a case-by-case basis where necessary and justified." See:

https://ec.europa.eu/info/law/better-regulation/have-your-say/initiatives/12418-Digital-Services-Actpackage-ex-ante-regulatory-instrument-of-very-large-online-platforms-acting-as-gatekeepers.
} 
A likely runner for 'New Competition Tool' (Option 3) appears to be broadly modelled on the UK's Market Investigation powers under the Enterprise Act 2002. These enable the UK Competition and Markets Authority (CMA) to identify and remedy situations in which there are 'features of a market' that create an 'adverse effect on competition'.

What should we think about such an introduction of a Market Investigation tool in this context? Is it likely to be a valuable complement to the Commission's existing competition powers? Will it be a panacea for digital competition concerns?

This article reflects on these questions, based on recent UK experience of market investigations. As discussed in Section 2, the tool has major positives and would be a valuable addition to the Commission's toolkit, in digital markets and more widely. However, as discussed in Section 3, the Market Investigation tool also has limitations. As was concluded in the 2019 UK Unlocking Digital Competition report, and should not be viewed as a full solution to digital platform issues. In particular, although it has huge flexibility in designing and implementing remedies, the process of monitoring, enforcing and revisiting these remedies over time has some important limitations. For this reason there is clearly a role for the ex ante regulation of digital markets, as a complement to Market Investigations. Section 4 considers the complementary nature of these tools in digital markets, taking interoperability as an example where they could valuably used alongside each other.

In focusing on the UK situation, this article does not endeavour to consider the complexities of introducing this tool at EC level. Nevertheless, certain aspects of the UK system may well be relevant to its effectiveness. The fact that the CMA has both competition and consumer powers is valuable, since many market studies effectively address issues that would otherwise 'fall through the cracks' between these two areas of law. The UK's system of concurrency between the CMA and sector regulators is also important, at least for the monitoring and enforcement of Market Investigation remedies in these sectors.

The statutory requirements around governance within the UK process are also relevant, and specifically the need for separation between the decision-makers who decide to commence a Market Investigation, following an initial market study, and those reach findings at the end of a Market Investigation. Finally, the international context for intervention may of course be different at EC level than for the CMA as a UK-focused authority.

\section{Positives of the Market Investigation tool}

In the UK, Market Investigations are used as a complementary instrument alongside other competition powers, and this would also be the case at EU level. So what advantages does this tool have in this context? What can it do that existing EC competition law cannot? The remarks below consider some key benefits in relation to scope, remedies and procedure.

(i) Scope

While standard competition powers and Market Investigations are both focused on improving competition, there are number of subtle but important differences between them in terms of scope. 


\section{A proactive role in promoting competition}

Most competition law provisions are primarily focused on preventing competition from becoming worsened, for example through mergers, collusion or abuse of dominance. A valuable contribution of Market Investigations is that they can play a more proactive role in promoting increased competition. So, for example, they can introduce market opening measures that are intended to shift the whole nature of competition. The Open Banking measures which arose from the UK Retail Banking Market Investigation are a good example, in that they were designed to open up the potential for disruptive and innovative competition from new technologies and business models.

\section{A broader and more holistic approach}

Standard competition law is primarily focused on the conduct of firms, albeit this conduct is considered within its market context and thus wider market characteristics can play a role. By contrast, Market Investigations are designed more broadly to tackle any and all 'features' of markets which are found to adversely affect competition. While such features can include firm conduct, they can also comprise factors such as economies of scale and scope, network effects, regulatory and structural barriers, and consumer behavioural factors. Remedies are frequently targeted at addressing these other factors, as opposed to restricting anticompetitive conduct by firms.

Market Investigations also allow for the investigation of a far wider set of competition concerns than the abuse of dominance and explicit collusion that are core target of standard competition law. Indeed, neither dominance nor explicit collusion have been found to be concerns in the CMA's most recent Market Investigations. ${ }^{6}$

On the supply side, for example, they can examine subtle complexities in the nature of strategic interdependence between firms, including the potential for tacit coordination. Indeed, the ability to examine 'tight oligopolies' is a key benefit of the regime. The 2014 Aggregates, Cement and Ready-mix Concrete Market Investigation is a good example. The Competition Commission (the CMA's precursor) identified a combination of structural and conduct features that were leading to coordination and higher prices. These were addressed through clear structural measures (divestment and market transparency reduction), rather than via more direct, but arguably harder to police, behavioural requirements on firms to cease colluding. Market Investigations can also consider the implications for firm incentives of factors such as vertical integration, principal-agent issues or regulatory barriers.

On the demand side, meanwhile, Market Investigations can consider firm conduct that might dampen or distort competition through making consumer decision-making difficult. Examples might include failing to provide clear and comparable information, refusing to deal with price comparison website services, including contractual terms that make switching costly or making the process of switching cumbersome. Firms can be required to

\footnotetext{
${ }^{6}$ These have examined Energy (final report, 2016), Retail Banking (2016), Investment Consultants (2018) and Funerals (ongoing).
} 
make changes to their conduct in these areas. While such factors may seem to have more in common with consumer law than competition law, they are not typically covered by consumer law and can have very significant implications for competition, even in relatively non-concentrated markets.

Market Investigations are especially well designed to carry out the holistic analysis of markets where problems are market-wide and there are a variety of interwoven factors structural and behavioural - creating competition concerns. By contrast, in standard competition cases, authorities tend to be funnelled into focusing more narrowly on one issue and (in abuse cases) one firm.

Market Investigations can also address markets can which have become 'stuck' in bad equilibria, which are good for neither firms nor society, but where some form of intervention is required to make the shift to a better equilibrium. For example, it may not be in the interest of any individual energy company to make it easier for their own consumers to switch supplier, even if the whole market would work more effectively and consumer trust would be increased if switching was generally easier.

\section{No role for culpability or intent}

Even to the extent that firm conduct is relevant, the focus of Market Investigations is firmly on anti-competitive effects. It is not relevant for Market Investigations whether conduct it is deliberately anti-competitive or whether firms are otherwise culpable for the harm. Indeed, even if the conduct in question creates efficiency benefits for consumers over the short term, and thus may well reflect a short run pro-consumer focus on the part of firms, it could still be found to create an adverse effect on competition if there is likely to be a consequent loss of competition that would harm consumers over the medium to long term. By contrast, while the role of intent in abuse of dominance cases is somewhat ill-defined, it is typically considered hard to sanction a firm that can show it is acting in its own short-run interest, with no strategic anti-competitive intent, or at least a finding of culpability.

\section{No need to fit within antitrust precedent or policy}

The targeted market-specific nature of Market Investigation analysis and remedies, and the lack of any need to show culpability, means that only limited consideration is given to wider deterrence and precedence. This could be seen as a negative, given the important role that wider deterrence plays in competition law generally and in providing legal certainty for firms. However, it does provide for more freedom to carry out economic analysis without being unduly constrained by the policy approaches and precedent from past cases.

For example, while the Market Investigation process does involve a market definition exercise, this is not given the same weight as it is in abuse of dominance cases. The focus is quite properly on the analysis of competitive constraints. (This should of course also be the case in competition law more widely but in practice is not).

It also means that Market Investigations are better able than standard competition law to consider the wider context, and in particular the complex interplay between competition 
and other policy areas such as privacy, consumer policy and fairness, and environmental issues. The CMA is especially alert to these links, given its dual role as a competition and consumer authority, and the UK system of concurrency with sector regulators.

\section{Implications for digital markets}

This ability to look at a panoply of interrelated issues across a market, or markets ${ }^{7}$, without any need to demonstrate culpability, is likely to be especially useful in digital platform markets. As was highlighted in the 2019 Unlocking Digital Competition report: "The challenges to effective competition in digital markets do not come about solely because of platforms' anti-competitive behaviour and acquisition strategies."

In these markets, the issues frequently arise from a combination of complex interleaving of firm conduct, consumer behaviour, economic characteristics, technological factors, and various aspects of regulation. Promoting competition in this sector will therefore not be purely about limiting anti-competitive conduct, important as that is. It will also require more proactive measures.

The Commission's Inception Impact Assessment for its proposed New Competition Tool highlights the potential to use the tool in relation to (i) markets displaying systemic failures going beyond the conduct of a particular company with market power or (ii) oligopolistic market structures with an increased risk for tacit collusion. Both of these objectives fit well with past experience of the Market Investigation regime.

The Commission's Impact Assessment also emphasises the potential use of the tool to intervene early to prevent markets from tipping, an issue of particular relevance in markets that exhibit strong network effects, such as digital platform markets. It is entirely true that such interventions may be difficult to make under standard competition law, given the absence of existing single firm dominance. However, it should be admitted that the UK has limited experience of using Market Investigations to this particular end.

The ability to consider carefully the synergies and tensions between interrelated policy objectives is likely to be important in digital markets, for example given the importance of consumer data and thus the relevance of privacy policy.

The reduced role played by market definition may also be valuable in digital markets, given the complexities involved in a formal market definition process in this context. These largely arise from the wide spectrum of organisational types and relations we observe. We know that digital players can compete despite some having closed ecosystems while others have open; despite some acting only on one side of a market, while others are multi-sided; despite some being integrated into interface activities, while others are stand-alone. These factors are important to examine carefully when assessing competition, but it is unhelpful to unduly constrain this analysis by forcing it into a narrow market definition exercise. Indeed, it could be argued that a weakness of competition law - and especially abuse of dominance

\footnotetext{
${ }^{7}$ The scope of Market Investigation powers was extended to allow the investigation of cross-market practices (as opposed to specific defined markets) by the Enterprise and Regulatory Reform Act 2013. This wider scope has, however, not yet been used.
} 
provisions - is that the legal framework requires the boundaries of firms and markets to be defined in unrealistically black-and-white terms.

\section{(ii) Remedies}

The discussion above focused on comparing Market Investigations with standard competition law. However, the European Commission is of course already able to carry out Sector Inquiries, which have significant similarities with Market Investigations. So what incremental benefits do Market Investigations bring?

Traditionally, an important aspect of the UK Market Investigation regime was that it included powerful information gathering powers, which could be used to 'shine a light' into markets in order to understand the barriers to competition that may exist. Since 2014, however, the CMA now has the same powers in respect of its market studies. Market studies can precede a Market Investigation, as a form of first stage review, but they can also be stand-alone reviews. As such, they are similar to the European Commission's own Sector Inquiries, albeit the Commission has the additional ability to carry out dawn raids, a power which is not available to the CMA for either market studies or Market Investigations. Like EC Sector inquiries, UK market studies can also be useful for generating recommendations for legislation, advocacy, or enforcement.

As such, the primary additional benefits of Market Investigations - over both UK market studies and EC Sector Inquiries - derive from its formal remedy-making powers.

\section{A broad remedy toolkit}

If an adverse effect on competition is identified, the CMA is required to achieve as comprehensive a solution as is reasonable and practicable. The toolkit of potential Market Investigation remedies is extremely broad, so long as they are effective and proportionate to the identified concerns. ${ }^{8}$ The main limitations are the requirement to target Orders at identified firms, which limits the potential to introduce non-firm-specific horizontal regulation ${ }^{9}$, and (to date at least) the need to respect EC Modernisation and EC maximum harmonisation provisions. ${ }^{10}$

This breadth of opportunity could be viewed negatively, as allowing excessive scope for intervention. Indeed, the sorts of interventions imposed through Market Investigations can be similar to those more typically imposed in other jurisdictions though legislation, but

\footnotetext{
${ }^{8}$ Remedies can be agreed with firms through undertakings or imposed on firms through Orders. While the provisions that can be imposed through Orders are formally constrained by legislation, the wording is sufficiently broad to allow most options. (See Enterprise Act 2002, Schedule 8). There is no constraint on what can be imposed through undertakings.

${ }^{9}$ Although note that Market Investigations can also lead to recommendations to Government to introduce such regulation.

${ }^{10}$ EC Modernisation provisions limit the ability of the CMA to impose remedies in relation to agreements which would be exempt from EC competition law, most relevantly vertical restraints which fall under the vertical restraints block exemption. EC maximum harmonisation provisions, such as within consumer protection or financial services regulations, may limit the ability of the CMA to impose more intrusive remedies than already required by law in some areas.
} 
without any process of parliamentary review. ${ }^{11}$ This reflects a wider UK focus on enabling competition-focused interventions, free of political consideration, but is also partly why there are tight checks and balances within the Market Investigation process, as discussed further below.

However, the breadth of potential remedies also brings clear benefits. While standard competition law remedies tend to be narrow and backward-looking, Market Investigation remedies can be forward-looking and market-wide, with remedies frequently applying across the market, irrespective of individual firm market power. A package of remedies may be used to address different aspects of market failure. Supply-side measures may be utilised to reduce market power directly or to limit the potential for its exploitation, for example through tacit collusion or exclusionary behaviour. Demand side remedies are designed to enhance consumer engagement and decision-making, through improved disclosure requirements and facilitating consumer search and switching, or to protect consumers against unfair treatment.

Market Investigation remedies can potentially also extend beyond a specific example of an issue that has been analysed, so long as this can be justified through the economic analysis. Again, this is potentially relevant to digital platforms. At the completion of the Google Shopping case, DG Competition was only able to impose a remedy relating to Google Shopping. It could not extrapolate from its findings and impose rules relating to analogous behaviour by Google in other vertical search markets such as job search, hotel search or local search. It is true that follow-on cases are easier to bring once an initial decision has been reached, but each case still needs to be assessed and proven individually. By contrast, a Market Investigation in this area might potentially have led to Orders which restricted Google from engaging in this sort of behaviour more generally, beyond the specific example of Google Shopping, so long as it could be shown that the same conclusions were likely to apply.

It is worth noting that, where the Orders arising from Market Investigations are behavioural, they effectively constitute a form of ex ante regulation in that they govern future firms' behaviour. This is true for both supply-side remedies such a transparency reduction requirements and demand-side remedies such as disclosure requirements.

This ability to introduce small-scale ex ante regulation can be especially valuable in markets which require intervention in order to work more effectively, but which are not covered by a sector regulator. It can also be a valuable complementary tool in regulated markets, where the issue in question is not within the scope of the regulation, or where the regulator does not otherwise have the requisite powers to address it.

Table 1, setting out a non-exhaustive selection of Market Investigation remedies, provides a flavour of the range of different remedies that may be utilised in market investigations.

\footnotetext{
${ }^{11}$ Some Market Investigations have in fact been followed by domestic and/or EU legislation that supersedes the original remedies, and the CMA has an ongoing programme of reviewing and sometimes revoking old Orders, partly for this reason. See: https://www.gov.uk/cma-cases?case_type\%5B\%5D=review-of-orders-andundertakings.
} 


\begin{tabular}{|c|c|c|}
\hline \multirow[t]{3}{*}{$\begin{array}{l}\text { Regulatory } \\
\text { remedies }\end{array}$} & $\begin{array}{l}\text { Changes to regulatory } \\
\text { framework }\end{array}$ & $\begin{array}{l}\text { Airports, Groceries, Local Buses, Audit, } \\
\text { Energy }\end{array}$ \\
\hline & Improved info for regulators & Airports \\
\hline & Price regulation & $\begin{array}{l}\text { Classified Directories, Energy (pre- } \\
\text { payment customers) }\end{array}$ \\
\hline \multirow[t]{6}{*}{$\begin{array}{l}\text { Demand-side } \\
\text { remedies }\end{array}$} & Disclosure requirements & $\begin{array}{l}\text { Liquified Petroleum Gas (LPG), Home } \\
\text { credit, Store Cards, Private Healthcare, } \\
\text { Motor Insurance, Banking }\end{array}$ \\
\hline & $\begin{array}{l}\text { Measures to facilitate/ } \\
\text { enhance search }\end{array}$ & $\begin{array}{l}\text { Home credit, Payment Protection } \\
\text { Insurance (PPI), Audit, Payday, Extended } \\
\text { warranties, Banking }\end{array}$ \\
\hline & $\begin{array}{l}\text { Measures to improve } \\
\text { consumer engagement or } \\
\text { switching }\end{array}$ & $\begin{array}{l}\text { LPG, Extended Warranties. Home Credit, } \\
\text { Banking, Energy }\end{array}$ \\
\hline & Fair terms for consumers & $\begin{array}{l}\text { Home Credit, Extended Warranties, } \\
\text { Store Cards, Banking }\end{array}$ \\
\hline & Point-of-sale prohibition & PPI \\
\hline & Data portability & Banking (Open Banking) \\
\hline \multirow{5}{*}{$\begin{array}{l}\text { Supply-side } \\
\text { remedies }\end{array}$} & Access to key inputs & Local buses \\
\hline & Transparency reduction & Aggregates \\
\hline & Unbundling & PPI, Store Cards, LPG \\
\hline & $\begin{array}{l}\text { Limits on restrictions in } \\
\text { agreements }\end{array}$ & Groceries, Audit, Motor Insurance \\
\hline & Limits on referral incentives & Private Healthcare \\
\hline \multirow{3}{*}{$\begin{array}{l}\text { Structural } \\
\text { remedies }\end{array}$} & Divestment & Airports, Aggregates \\
\hline & $\begin{array}{l}\text { Market share/expansion } \\
\text { limits }\end{array}$ & Classified Directories, Groceries \\
\hline & Market redesign & Energy (settlement market) \\
\hline
\end{tabular}

Finally, while interventions are typically designed to enhance competition, they can also be used to protect consumers from the harm arising from limited competition. For example, the CMA introduce a safeguard price cap for pre-payment energy customers following the Market Investigation into the energy market. These customers were found to be frequently vulnerable, relatively unlikely to switch provider, and at risk of exploitation.

\section{Structural remedies: A brief comment}

As is clear in the above table, the UK Market Investigation regime also allows for structural remedies to market problems. This power is much touted, but it is utilised rarely in practice. It can be difficult to demonstrate that such an interventionist remedy is required, as the CMA found to its cost in 2016 when it was forced to abandon its attempts to require 
hospital divestments, following an appeal and remittal in relation to its private healthcare Market Investigation.

Divestment is arguably most likely to be required in situations where firms have effectively found to be single-firm dominant (albeit that terminology is not used), such that it might have been feasible to extract similar remedies under existing EC competition law. However, it can be applied where a lack of competition is harming consumers, even if there is no clear abuse. An example might be the divestiture of London and Scottish airports which resulted from the BAA Airports Market Investigation. Here, the concerns related to weak investment and poor user-responsiveness, resulting from very high market shares and barriers to entry alongside inadequacies in the regulatory system. It is far from clear whether this would constitute abuse under Article 102.

That said, structural remedies can potentially be imposed in a wider set of circumstances, following a Market Investigation, if existing market structure if found to be contributing to an adverse effect on competition. The 2014 report requiring structural remedies in the UK aggregates sector was based on a careful economic analysis of the complex vertical oligopoly situation in the UK. It is not obvious that single firm dominance would have been found.

However, it is important that the existence of Market Investigations is not viewed as a rationale for weakening (or even not strengthening) the merger regime. While it is theoretically true that a Market Investigation could be used to unwind an anticompetitive merger, this would be bad public policy given the high costs involved in 'unscrambling' mergers post-integration. In a different but analogous context, this is shown by the difficulties experienced in trying to address breaches of state aid law in the UK banking sector through structural remedies.

\section{Implications for digital markets}

There are limitations to use the of Market Investigations in a digital context, as will be discussed further below. As such, the 2019 Unlocking Digital Competition report argued for the introduction of pro-competitive digital platform regulation rather than relying purely on the Market Investigation tool. The alternative - addressing concerns through a series of Market Investigations - would lead to a series of behavioural remedies that would require ongoing monitoring, and thus effectively turn the CMA into a mini-regulator by default anyway, but with the risk that such regulation would take a somewhat piecemeal and imperfect form. ${ }^{12}$

However, even with the introduction of pro-competitive digital platform regulation, it remains likely that Market Investigations will still have an important role to play in digital markets, with its likely focus depending partly on the powers and scope of the new regulation.

\footnotetext{
12 There are also funding implications. In the UK, sector regulators are typically funded by industry participants, so a specialist digital regulator would likely be funded by levies on designated firms. By contrast, the CMA is funded by UK taxpayers, with no powers to levy firms to fund its work in monitoring and enforcing remedies.
} 
The breadth of potential remedy types, and the ability to develop a package of remedies, is likely to be especially valuable, given the complex set of drivers for the issues arising in many digital markets. For example, data portability provisions, such as those introduced through the CMA's Open Banking remedy, may well be valuable for opening a number of digital platform markets, including social media. Other valuable supply-side remedies might include interoperability provisions, non-discrimination requirements, a ban on paying for default position, requirements to deal, or requirements to provide data access.

The demand-side is also very important in digital markets. As such, there may also be potential for remedies that improve consumer decision-making. For example, in its recent market study into Online Platforms and Digital Advertising, the CMA identified a number of possible remedies designed to given consumers greater control over their own data, including requiring the major platforms funded by digital advertising to be more transparent with consumers about the data they are providing and to ensure that the associated choice architecture really acts to facilitate informed consumer choice. ${ }^{13}$ One could also envisage more general remedies, applying to all platforms with very substantial market shares, to ensure that they do not unfairly utilise the choice architecture on their platforms, or unfairly design their algorithms, to steer consumers towards additional services or towards their own products.

Of course, as discussed above, structural separation through divestment is also a possibility. This could be a valuable option in certain digital markets, as could less intrusive forms of separation such as operational separation or requirements that are directly targeted at addressing conflicts of interest arising from integration.

\section{(iii) Procedure}

\section{Two-stage process with separate decision-making}

The independence and robustness of Market Investigations is bolstered by the associated governance. There is a clear split of decision making between the decision to refer a market for investigation, which is taken by the CMA Board, and the final Market Investigation decision, which are made by a Group of independent decision-makers, drawn from the CMA Panel. CMA Panel members are all highly experienced, non-political, and bring a diversity of expertise and viewpoints. They are not CMA staff. The Group members for each Market Investigation are named publicly.

Market Investigations effectively constitute the second phase of a two-stage process. The first stage, which takes the form of a 12-month market study, carries out initial market analysis and considers whether a market investigation 'reference' is warranted. ${ }^{14}$ Prior to the creation of the CMA, the two phases occurred in two separate bodies; the market study and referral decision were taken by the Office of Fair Trading and the investigation was carried out by the Competition Commission. To limit the risk of confirmation bias within the CMA, post-merger, rules require that there is no overlap of people between the Board

\footnotetext{
${ }^{13}$ CMA, Online Platforms and Digital Advertising: Market Study Final Report, 1 July 2020.

${ }^{14}$ Market Investigations are sometimes known as Market InvestigationRs (or Market Investigation References) for this reason.
} 
members who take the reference decision and the Group members taking the final Market Investigation decision.

As well as limiting confirmation bias, this two-stage process is also valuable for avoiding the Market Investigation process becoming a depository for unpopular political issues that no one else wants to tackle. These will typically be considered through a market study instead. This affords the CMA the same investigatory powers as a Market Investigation, but none of the formal remedial powers.

The two-stage process can also be utilised to extract formal undertakings from parties at the end of a market study in lieu of a Market Investigation reference. For example, the UK telecoms regulator has utilised this process to extract undertaking from telecoms infrastructure provider, Openreach. Like the European Commission's own Sector Inquiries, market studies can also lead to recommendations to Government or sector regulators, advocacy, guidance or enforcement action, without any Market Investigation reference being made.

\section{Transparency}

An important positive of Market Investigations is that the overall procedure is very transparent. During the process, the CMA will publish: an initial issues statement; working papers and an annotated issues statement; provisional findings and possible remedies notice (if relevant); provisional decision on remedies (if relevant); and a final report. Any interested party can comment on the intermediate documents. While confidential information will be redacted, sufficient information will typically be made public to allow effective consideration of the issues. Responses from parties are typically also published. There are hearings with parties at key stages, attended by the full decision-making Group.

\section{A more participative approach}

This level of transparency is substantially greater than that in standard competition law and allows for a robust and participative approach. Indeed, while market investigations clearly need to be well-evidenced and robust and issues are hard-fought, the engagement between the CMA and parties nevertheless tends to be more open, less adversarial and less legalistic in Market Investigations than in standard competition law cases relating to abuse of dominance or anti-competitive agreements.

As well as transparency, this less adversarial approach may reflect the economic focus of the analysis, the very limited role played by legal precedent, and also the fact that market investigations can end up anywhere - including a finding of no adverse effect on competition - so parties have much to gain from engaging openly with the process. Remedies can even turn out to be unexpectedly positive for firms. The early (1993) requirement on British Gas to divest its distribution business is a case in point. The combined valuation of the two separate companies quickly exceeded that of the original vertically integrated incumbent. Moreover, good remedies can make the market work better, and firms will understand this even they don't necessarily like it. 
Market Investigations also seem to be less subject to appeal and standard competition law cases. This difference of approach may partly reflect the different appeal standard in the UK; Market Investigation findings can be appealed on a Judicial Review (JR) basis only, while Competition Act 1998 cases receive a Full Merits review. In the context of such a JR, the high levels of transparency and other procedural safeguards could also play a role. Certainly, appellants have rarely been successful in challenging Market Investigation decisions, and from the authority's successes, it is clear that the CMA has a wide margin of appreciation with its diagnosis of problems and judgement as to which remedies are effective and proportionate.

Another relevant factor is that there are no fines, and thus no quantum of penalty to be challenged on appeal. Perhaps less positively, an alternative explanation for the low number of appeals is that, with several companies involved, each one faces a free-rider problem in choosing whether to appeal; the appeal costs fall to the individual firm while the benefits of any appeal success would typically go to all.

\section{Limitations of the Market Investigation tool}

The above discussion, while focussed on the UK experience, clearly suggests that a Market Investigation regime could also have merit at EU level. However, it is also important to highlight some important limitations of the tool, not least because these might be useful when determining its precise design.

\section{Timetables and remedy testing}

Market Investigations must be completed within 18 months, albeit with the potential for extension by another six months. The final report, at the end of this period, must include not only the substantive findings but also any remedies to be imposed, together with the underlying evidence for both.

There are some positives from a tight timeline. It helps to engage minds; early intervention can reduce extent of consumer detriment; and it can be especially important to intervene quickly if competition concerns are worsening over time, for example because a market is quickly - but avoidably - tipping towards monopoly. It has also proven to be possible to complete a reasonably robust analysis of the substantive market issues within this timeframe, greatly aided by the initial market analysis that is carried out at the market study phase of the process which can take up to a year and occurs prior to reference.

What has proven harder is to carry out effective remedy design on such a tight timetable. In the past, this issue was exacerbated by a policy approach which determined that remedies should not be considered until adverse findings had been identified. While such an approach might appear reasonable, it is simply impracticable. Remedy design is complex, and it is easy to get it wrong. As such, potential remedies are now considered from the start of the process, and sometimes even (informally) before the formal Market Investigation launch. 
While this is a positive change, the available time is still frequently insufficient for designing complex remedies or properly piloting remedies, for example through the use of randomised controlled trials. That said, creative solutions may be available. For the consumer engagement remedies arising in the recent energy and banking Market Investigations, the final remedy design, testing and implementation was left to the relevant sector regulators, who could take the required time to do this properly. The CMA imposed on the parties a requirement to engage with such trials. Likewise, due to the complexity and likely time and resources involved in its Open Banking remedy, the CMA required that a new entity be set up and tasked with the detailed design and implementation of the remedy.

\section{Limited flexibility to revisit remedies}

A more serious problem with the Market Investigation regime is that remedies cannot be revisited once they have been formally imposed, if they are found to be imperfectly designed or ineffective. There is only a provision for parties to request that remedies be altered or removed if they can demonstrate that there has been a 'material change in circumstances' since they were imposed.

In considering the impact of this inability to alter a remedy package, it is interesting to note the parallel experience of market studies carried out by the UK Financial Conduct Authority. These can also give rise to remedies, but because this is done through changes to regulatory rules, there is flexibility to trial remedies and revisit. In some cases, the FCA has completely abandoned specific remedy proposals, following testing, and the remedy package has been (or is being) substantially revised to make it more effective.

Such flexibility is arguably in the interest of both firms and consumers; no one gains from costly, ineffective regulation. The CMA recently highlighted that there may be potential for a change in its powers which would enable it, within a fixed period of time, to revisit its remedy package while continuing to rely on its substantive findings on competition. ${ }^{15}$

The inability to flex remedies may be especially problematic in dynamic markets which are subject to significant change. In such markets, the identified concerns may be fairly persistent (although this is not a given), but the appropriate remedies may well require flexing as the markets and technologies change.

\section{Limitations to remedy enforcement}

Since the majority of Market Investigation remedies are behavioural and quasi-regulatory, there needs to be some process for monitoring and enforcing them. In markets which are overseen by sector regulators, this task can potentially be passed to them, to be carried out alongside other monitoring and enforcement activity.

\footnotetext{
${ }^{15}$ See letter to then Secretary of State Greg Clark MP from CMA Chair Lord Andrew Tyrie, 21 February 2019, footnote 27.

https://assets.publishing.service.gov.uk/government/uploads/system/uploads/attachment_data/file/781151/ Letter from Andrew Tyrie to the Secretary of State BEIS.pdf.
} 
In other markets, the CMA has an experienced and expert remedy monitoring team to manage this process. The ability to impose reporting requirements as part of a remedy can be valuable for facilitating this process and maximising the impact of the CMA resources involved. In a number of instances, the CMA has also used a third-party implementation or monitoring body, funded by the companies involved. For example, the Open Banking Implementation Entity was funded by the nine major UK banks and able to draw in technical expertise on standard-setting and implementation of APIs.

However, the resources and expertise required to carry out quasi-regulatory remedies monitoring in a complex environment should not be understated. In a digital context, with the potential for market interventions relating to highly complex areas such as interoperability, standard-setting and algorithmic design, the required monitoring could quickly start to look more like that carried out by the telecoms and financial regulators, rather than that typically done within the CMA's remedies team. This was another reason why the Unlocking Digital Competition report took the view that market investigations, while potentially useful, an ex ante regulator was also required.

A further limitation of the CMA's enforcement powers is that it has no direct ability to impose sanctions for breach. It can only go to Court to obtain a court order, breach of which could then be penalised. Even then the penalties are typically low. This is unlikely to provide effective enforcement mechanism for breaches, especially for large firms such as the major digital platforms. The CMA has written to Government requesting that this situation be changed. ${ }^{16}$

A final challenge arises where parties' assets are located outside the UK, or integrated into other parts of their global business. While the CMA can always impose Orders where they are relevant to the UK market, the monitoring and enforcement of compliance in such circumstances may be complex and entail legal proceedings in another jurisdiction. This may well be a relevant issue in digital markets, especially if different authorities take conflicting approaches to the same issues, creating a clear need for discussion and collaboration with international counterparties. In this regard, activity at European level - through a new competition tool - may prove rather easier than national-level interventions.

\section{Unduly high public expectations}

A final negative of Market Investigation is arguably more political than substantive. It is the corollary of one of the major positives; the ability to impose very significant remedies. Unless expectations are very carefully managed, this can lead to the build-up of unduly high expectations around Market Investigations, which can in turn generate intense dissatisfaction with the CMA's performance when it concludes that only moderate remedies are justified. The CMA faced substantial criticism of this sort in 2016, at the conclusion of two major market investigations into retail banking and energy.

There can also be a need to manage expectations about the likely speed and scale of impact for Market Investigation remedies. In some markets, while remedies can reduce the extent

\footnotetext{
${ }^{16}$ Ibid, page 16.
} 
of competition problems, they may not be able to overcome them entirely. Meanwhile, some remedies - indeed, often the better remedies such as Open Banking - can take some time to be effective.

\section{Implications for digital markets}

The limitations outlined above led the Unlocking Digital Competition report to conclude that Market Investigations, while potentially useful in digital markets and more widely, were unlikely to provide a complete solution in digital platform markets. The most relevant concerns relate to flexibility of remedy design, the resources likely to be taken up in monitoring remedies, limited enforcement powers, and complexities associated with the global nature of the major digital tech companies and their assets

\section{Digital: A Complementary role for Market Investigations and ex ante regulation}

Recognising these limitations, the Unlocking Digital Competition report proposed ex ante regulation for the major digital platforms, to act alongside the Market Investigation regime. The CMA has taken a similar stance. At the conclusion of its market study in Online Platforms and Digital Advertising, the CMA decided not to commence a formal market investigation. It did so on the basis that the UK Government was expected to be introducing ex ante regulation in this area and that it would be preferable to intervene via that route so far as possible.

It is therefore to be welcomed that the Commission is also consulting on the potential for a new ex ante regulatory instrument for large digital platforms. But this leaves a residual question. In the context of digital platforms, would there be merit in the EU also introducing the New Competition Tool as a complement to such ex ante regulation? There is certainly a rationale for doing so.

\section{Market Investigations in the context of regulation?}

The incremental value of Market Investigations in the context of regulation will clearly depend on the powers to be incorporated within such any ex ante regulatory framework. Option 3 is the key option in the European Commission's proposals, and it has two potential elements. Sub-option 3a would involve the "prohibition or restriction of certain unfair trading practices by large online platforms acting as gatekeepers ("blacklisted" practices)'. Sub-option $3 b$ would enable the adoption of 'tailor-made remedies addressed to large online platforms acting as gatekeepers on a case-by-case basis where necessary and justified'.

While either type of intervention could potentially emerge from a Market Investigation, Sub-option $3 \mathrm{~b}$ is clearly the more similar in that it would involve reviewing specific market issues and imposing proportionate tailored remedies.

However, there are at least three substantive areas where there is a potential gap in the Commission's proposals for ex ante regulation, and which could the New Competition Tool could usefully fill. 
The first gap relates to the power to impose structural interventions. These are apparently envisaged as a possible outcome in relation to the New Competition Tool, but are not mentioned in the consultation on ex ante regulation.

As mentioned above, structural interventions have in fact been imposed only rarely in Market Investigations. However, it is noteworthy that the CMA Online Platforms and Digital Advertising market study identified a serious conflict of interest associated with Google's strong position at various levels in the advertising intermediation value chain. It concluded that the proposed UK regulator should have the power to introduce different forms of separation, from operational separation to full ownership separation. The CMA's findings thus confirm that the power to impose structural remedies may well prove valuable but also highlight that this power could potentially be given to a regulator, rather than reserved for Market Investigations.

The second gap relates to the potential that smaller platforms may adversely affect competition, but do not meet the criteria for ex ante regulation of "large online platforms acting as gatekeepers". This could perhaps occur where a platform is an important gatekeeper, but in a niche market. In this case, the New Competition Tool provides an alternative route to a form of bespoke regulation. Indeed, given the concerns highlighted above around the monitoring, enforcement and review of the remedies flowing from market investigations, it may even be valuable to give the ex ante regulator powers to carry out on these follow-on activities where digital gatekeeper platforms are involved.

The third gap relates to the need for market-wide interventions to promote competition. It would clearly be possible to impose certain ex ante regulations symmetrically to all market participants, as indeed occurs under the EU Regulatory Framework for communications. However, the ex ante regulation instrument that is currently proposed would allow requirements to be placed only on the largest digital platforms. Since interventions will be best applied to all firms across a market, this may provide a valuable role for a Market Investigation.

Market-wide interventions can be important even where there is a single firm with a dominant position. Consider the simple example of telephone number portability. This is now a standard element of telecommunications regulation, but it was first imposed in the UK in 1995, following a Market Investigation-like review. Making this a market-wide requirement, rather than simply imposing it on the incumbent supplier British Telecom, was important for giving consumers confidence that they could keep their phone number not only if they switched away from the incumbent but also if they later switched back.

This was a situation where a market-wide intervention was required in order to open up competition to a strong incumbent supplier, but - as the discussion above highlights market-wide interventions can also be valuable for enhancing competition when there are multiple players in a market. Indeed, number portability itself is today required in mobile telephony markets, where there are typically multiple players. It is important for facilitating the switching required for effective competition and it has been shown to have a substantial 
impact in reducing prices. ${ }^{17}$ The majority of the Market Investigation interventions in the Table 1 above were applied to multiple firms across the market, and designed to enhance competition generally rather than specifically to open up monopolised markets.

As is emphasised in the Commission's Inception Impact Assessment, market-wide interventions can also be valuable in preventing markets from tipping. Again, the telecommunications sector offers a useful example, with the rules around interconnection being valuable in ensuring a level playing field for competition that overcomes the tendency towards concentration that would otherwise exist. Consider an alternative world in which there were no ability to interconnect across mobile telephony networks. In that world, the natural consumer desire to access as wide a network of contacts as possible would likely result in the market tipping to monopoly.

\section{Thought experiment: The case of interoperability}

The complementary role that the two proposed tools might play can be considered through a thought experiment. Consider the thorny issue of interoperability. Like number portability, interoperability can be valuable both in opening up a monopolised market to competition and also in facilitating effective competition within a non-monopolised market. In the former case, it may potentially be sufficient to impose interoperability only on the monopoly firm, but in either case it may also be valuable to impose it more widely.

Interoperability can also work to prevent currently non-monopolised digital markets from 'tipping' to monopoly, for much the same reasons as interconnectivity in telecoms. This has an important implication: it may be valuable to impose interoperability at an early stage in the development of a market. ${ }^{18} \mathrm{~A}$ current example might be the market for self-driving cars, where such a requirement may be important for generating effective competition, and indeed maximising safety.

Given these competition benefits of interoperability, there have been many demands that the digital platforms should make their systems interoperable. But what does this really mean? It presumably cannot mean that every element of their systems is made fully interoperable; this would not be justified by the competition concerns, even if made sense as a concept.

One could, however, imagine the following three-pronged regulatory approach being taken to interoperability, which would draw upon both the ex ante regulatory instrument and the New Competition Tool proposed by the Commission:

1) Under Option 3a of the proposed ex ante regulatory instrument: Blacklisted practices for designated major platforms such as:

\footnotetext{
17 Park, M. (2011), The Economic Impact of Wireless Number Portability. Journal of Industrial Economics, 59: 714-745. doi:10.1111/j.1467-6451.2011.00471.x

${ }^{18}$ Absent interoperability, multi-homing by users can have a similar effect, and it can equally be important to protect or promote that.
} 
- where a designated digital platform offers interoperability to one or more third parties, failing to offer the same functionality to all other third parties or doing so on a discriminatory basis;

- where a designated digital platform has previously provided interoperability to a third party, later withholding, withdrawing or deprecating this, where doing so would have an adverse effect on platform users; or

- failure to ensure that the core technologies of any designated digital platform interoperate effectively with third party technologies, where this would bring user benefit.

2) Under Option 3b of the proposed ex ante regulatory instrument: Specific requirements on designated platforms to provide interoperability in relation to particular areas, designed to open up competition. An example might be a requirement on a designated social media platform to enable cross-posting, as proposed by the CMA in its Online Platforms and Digital Advertising market study.

3) Under the proposed New Competition Tool: Requirements for cross-market interoperability, which apply to all market participants, not just designated digital platforms. This may also require cross-industry coordination on standards and protocols, a process which can itself raise competition concerns and which may benefit from careful oversight.

In theory, all of these interventions could be achieved through Market Investigations. However, the issues of flexibility and monitoring described above mean that the design and enforcement of the first and second are likely to be better suited to the application of an ex ante regulatory framework.

\section{A final word}

In 2002, the UK sent a delegation ${ }^{19}$ to DG Competition to present and promote the UK's Market Investigation regime. They failed to convince their hosts of the advantage of this tool relative to standard competition law, and they were sent packing.

In the intervening 18 years, we have all learned a lot. The potential of Market Investigations has been more thoroughly tested, while the limitations of standard competition law, and especially abuse of dominance provisions, have become more apparent. The Commission's consultation on a New Competition Tool is therefore both welcome and timely. There are lessons to be drawn from the UK experience of Market Investigations for the implementation of such a regime at EU level. For example, because the tool is potentially so powerful and flexible, it merits strong procedural checks and balances, to guard against confirmation bias or politicisation. At the same time, there is significant room for improvement within the current UK regime in relation to the powers around remedy flexibility and enforcement.

\footnotetext{
${ }^{19}$ The delegation included the author in her then role as Chief Economist at the Office of Fair Trading
} 
Nonetheless, the UK experience also confirms that the New Competition Tool has the potential to be hugely helpful, both in the digital sphere and more widely. But the tool also has inherent limitations and thus should not be viewed as a full solution to the issues raised by digital platforms, but rather as a valuable complementary tool alongside new ex ante regulation. 